\title{
Response of gonococcal clinical isolates to acidic conditions
}

\author{
R. K. PETTIT, S. C. McAlLISTER* and TRACI A. HAMER* \\ Cancer Research Institute and Department of Microbiology, Arizona State University, Tempe, AZ 85287-1604 \\ and ${ }^{*}$ Department of Biology, Western Oregon University, Monmouth, Oregon 97361, USA
}

\begin{abstract}
This study examined the response to acidic conditions of four gonococcal isolates NRL38874 (Proto/IB-2), NRL38884 (Pro/IA-2), NRL38953 (Proto/IB-3) and NRL39029 (Pro/IA-3) - obtained from various sites in patients in whom a diagnosis of pelvic inflammatory disease had been made by laparoscopic examination. Acid tolerance of the clinical isolates was strain and growth phase dependent. Growth of the four strains on solid media was undetectable below pH 5.8. In liquid culture, strain NRL38884 did not survive below pH 5.2; strains NRL38874, NRL38953 and NRL39029 survived to pH 4.5. Between pH 4.2 and $\mathrm{pH}$ 5.1, the latter three strains exhibited a peak in survival at pH 4.6-4.7 during log phase, suggesting that there may be a distinct acid tolerance system operating at this pH. SDS-PAGE of whole-cell, total membrane and outer-membrane fractions of the four strains prepared from $\mathrm{pH} 7.2$ and $\mathrm{pH}$ 6.1 plate cultures revealed numerous differences in protein composition. Acidic conditions reduced the expression of the reduction modifiable outer-membrane protein $\mathrm{Rmp}$, and induced the expression of many membrane proteins, including gonococcal hsp63. Immunoblotting studies with matched serum samples and strains from patients with pelvic inflammatory disease indicated that IgG recognition of outer-membrane components from strains cultured in acidic and neutral conditions was quite different. The results suggest that the immune system interacts with unique outer-membrane constituents on gonococci colonising sites at different $\mathrm{pH}$.
\end{abstract}

\section{Introduction}

To colonise genital mucosa and survive killing in neutrophil phagosomes, Neisseria gonorrhoeae must contend with temperature and nutrient fluctuations, anaerobiosis, reactive oxygen intermediates and acidic $\mathrm{pH}$. In vitro, all these stress conditions result in altered protein expression. Thermal stress induces the gonococcal homologues of major Escherichia coli heat-shock proteins (hsps) DnaK and GroEL (hsp60) [1], and nutrient stress induces the gonococcal homologue of GroEL, known as hsp63 [2]. In contrast, anaerobic conditions induce three novel proteins that bear no sequence similarity to GroEL or DnaK [3]. Exposure of gonococci to $\mathrm{H}_{2} \mathrm{O}_{2}$ or neutrophils results in an increase in catalase expression [4]. A previous study demonstrated increased expression of hsp63 in response to acid stress in $N$. gonorrhoeae strain FA19

Received 24 Nov. 1997; revised version accepted 18 May 1998.

Corresponding author: Dr R. K. Pettit.
[5]. Stress-inducible proteins may affect survival of gonococci and pathogenesis of infection in the urogenital tract.

In one type of complicated gonococcal infection, pelvic inflammatory disease (PID), $N$. gonorrhoeae spreads from the vagina or cervix to the fallopian tubes or other pelvic organs. This ascent exposes the gonococcus to immunological barriers, as well as to

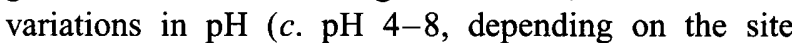
and the stage of the menstrual cycle) and nutrient and oxygen availability. Several observations support the hypothesis that $\mathrm{pH}$ affects the pathogenesis of gonococcal infections: strains grown at acidic $\mathrm{pH}$ have decreased surface hydrophobicity and increased negative surface charge [6], adherence of intact gonococci and purified gonococcal pili to vaginal epithelial cells has a $\mathrm{pH}$ optimum of $4.5[7,8]$, and the gonococcal sialyltransferase has a $\mathrm{pH}$ optimum of 5.8 [9]. This report describes evidence for in-vivo expression of acid stress proteins in four gonococcal clinical isolates and the acid survival limits of these strains. 


\section{Materials and methods}

\section{Strains}

Strains NRL38953, NRL39029, NRL38874 and NRL 38884 were isolated from patients with laparascopically confirmed gonococcal PID (Table 1). Strains were maintained on gonococcal typing agar (GC agar, neutral $\mathrm{pH}$ ) [10] at $37^{\circ} \mathrm{C}$ in air with $\mathrm{CO}_{2} 5 \%$. Nonpiliate, non-Opa-bearing organisms were selected [10]. Strains were subcultured no more than five times before each survival and membrane fractionation experiment.

\section{Sera}

Normal human serum (NHS) was obtained from a male with no history of exposure to $N$. gonorrhoeae. PID sera were obtained from the same patients as the strains (Table 1).

\section{Acid survival}

Mid-log or late stationary phase broth cultures ( $\mathrm{pH} 7.0$ ) were diluted to $(1-2) \times 10^{3} \mathrm{cfu} / 10 \mu \mathrm{l}$. This inoculum was introduced into $990 \mu \mathrm{l}$ of gonococcal typing broth (GC broth) [10] acidified to various $\mathrm{pH}$ values with $\mathrm{HCl}$ (the final $\mathrm{pH}$ of the broth stocks was obtained after sterilisation). The GC broth for these experiments did not contain supplement $(0.7 \mathrm{mM}$ glutamine, $5 \mathrm{mM}$ dextrose, $2 \mu \mathrm{M}$ thiamine pyrophosphate) or an additional $\mathrm{CO}_{2}$ source $\left(5 \mathrm{mM} \mathrm{NaHCO}_{3}\right)$. After exposure for $2 \mathrm{~h}$ (without shaking) to acid at $37^{\circ} \mathrm{C}$ in air with $\mathrm{CO}_{2}$ $5 \%$, bacteria were counted in duplicate on GC agar $(\mathrm{pH}$ 7.0 ), and percentage survival was calculated based on inoculum counts. Values $>100 \%$ indicated growth during the 2-h incubation period. Acid susceptibility assays were performed at least twice on different days. Although individual values varied in different experiments, the trend was consistent.

To confirm further the acid susceptibility trend, survival of strain NRL38953 was compared with and without supplement and $5 \mathrm{mM} \mathrm{NaHCO}_{3}$, and with both filter sterilised and autoclaved $\mathrm{GC}$ broth (the final $\mathrm{pH}$ of all preparations was determined after sterilisation).

\section{Membrane fractionation}

After incubation for $18-20 \mathrm{~h}$ on GC agar plates at $\mathrm{pH}$ 6.1 or 7.2 (buffer was modified for $\mathrm{pH}$ plates as described previously [11], and the $\mathrm{pH}$ of all prepara- tions was verified after sterilisation), cells were harvested in $\mathrm{pH} 6.1$ or $\mathrm{pH} 7.2$ buffer [11] containing phenylmethylsulphonyl fluoride (PMSF, $10 \mathrm{mM}$ ) $0.1 \% \mathrm{v} / \mathrm{v}$, diluted to identical optical densities and volumes, and washed in the appropriate buffer at $4^{\circ} \mathrm{C}$. Pellets were resuspended in $10 \mathrm{mM}$ HEPES (N-[2hydroxyethyl]piperazine- $\mathrm{N}^{\prime}$-[2-ethanesulphonic acid])PMSF, chilled and disrupted by sonication at $8 \mathrm{~W}$ for $10 \mathrm{~min}$ at $4^{\circ} \mathrm{C}$ (Fisher Model 60 Sonic Dismembrator). Cell debris was removed by centrifugation at $3000 \mathrm{~g}$ for $10 \mathrm{~min}$ at $4^{\circ} \mathrm{C}$. Total membranes were pelleted by centrifugation at $100000 \mathrm{~g}$ for $60 \mathrm{~min}$ at $4^{\circ} \mathrm{C}$, resuspended and incubated for $10 \mathrm{~min}$ at room temperature with Sarkosyl $1 \% \mathrm{w} / \mathrm{v}$ in $10 \mathrm{mM}$ HEPES-PMSF. Sarkosyl-insoluble outer membranes were pelleted by centrifugation at $100000 \mathrm{~g}$ for $60 \mathrm{~min}$ at $4^{\circ} \mathrm{C}$. Whole cells and total membranes were collected from the same preparations used to isolate outer membranes.

\section{$S D S-P A G E$}

Protein concentrations of solubilised [12] whole-cell, total membrane and outer-membrane pellets were determined by BCA (Pierce). Solubilised preparations were separated overnight in SDS-PAGE $10 \%$ gels (Hoefer) at $4^{\circ} \mathrm{C}$ with $15 \mathrm{~mA}$ constant current. Gels were stained with Coomassie Brilliant Blue or silver nitrate. Growth of $N$. gonorrhoeae at the various $\mathrm{pH}$ values followed by fractionation and SDS-PAGE was performed at least four times on separate days with consistent results.

\section{Western blotting}

For hsp blots, solubilised cell fractions from $\mathrm{pH} 6.1$ and $\mathrm{pH} 7.2 \mathrm{GC}$ agar cultures were electrophoresed in mini gels (BioRad Mini Protean II) $15 \%$ for $c .2 \mathrm{~h}$ at $76 \mathrm{~V}$ constant voltage, and transferred electrophoretically to nitrocellulose paper overnight at $0.7 \mathrm{~A}$ constant current in $20 \mathrm{mM}$ phosphate buffer, $\mathrm{pH} 8.0$. For detection of gonococcal hsp63, membranes were blocked for $1 \mathrm{~h}$ in Tween $200.05 \%$ in Dulbecco's phosphate-buffered saline (dPBS), incubated for $7 \mathrm{~h}$ with anti-Chlamydia hsp60 monoclonal antibody A57E4 [13] (generously provided by R. Morrison, Rocky Mountain Laboratories, NIH, NIAID), washed three times in dPBS/Tween 20, and probed with antimouse IgG peroxidase ( 1 in 1000; Sigma) for $2 \mathrm{~h}$. Blots were washed three times in $20 \mathrm{mM}$ Tris- $500 \mathrm{mM}$ $\mathrm{NaCl}(\mathrm{pH} 7.2)$ and developed. For detection of DnaJ, blots were blocked in skim milk 5\%/Tween $200.05 \%$

Table 1. Gonococcal clinical isolates and sera

\begin{tabular}{llllll}
\hline Strain no. & Isolation site & Por serovar & Auxotype & $\beta$-Lactamase \\
\hline NRL38953 & Fallopian tube & IB3 & Proto & Negative & ICD082 \\
NRL39029 & Endometrium & IA3 & Pro & Positive & ICD102 \\
NRL38874 & Cervix & IB2 & Proto & Negative & ICD108 \\
NRL38884 & Fallopian tube & IA2 & Pro & Negative & ICD109 \\
\hline
\end{tabular}

Strains, phenotypes and sera were provided by the Neisseria Reference Laboratory, Seattle, Washington, USA. 
in dPBS, incubated for $7 \mathrm{~h}$ with anti- $E$. coli $41 \mathrm{kDa}(1$ in 1000; SPA 410, StressGen), washed and probed with anti-rabbit IgG peroxidase (Sigma) for $2 \mathrm{~h}$.

For analysis of human antibody binding, solubilised preparations were separated in SDS-PAGE $10 \%$ gels overnight at $4^{\circ} \mathrm{C}$ with $15 \mathrm{~mA}$ constant current and transferred electrophoretically to nitrocellulose paper for $3 \mathrm{~h}$ at $1 \mathrm{~A}$ constant current in $20 \mathrm{mM}$ phosphate buffer, $\mathrm{pH}$ 8.0. Blots were blocked in skim milk $2.5 \%$ in dPBS, incubated overnight in NHS 7.5\% or PID serum $7.5 \%$ in blocker, washed three times, and probed for $3 \mathrm{~h}$ with 1 in 1000 anti-human $\operatorname{IgG}$ or $\operatorname{IgA}$ peroxidase (Sigma) in blocker. No antibody binding was detected in control blots lacking incubation with human serum.

\section{Results}

\section{Acid survival}

As $N$. gonorrhoeae is exposed to various $\mathrm{pH}$ values during transmission and infection, this study investigated the acid tolerance limits of four clinical isolates. Survival of the four isolates decreased from $\mathrm{pH} 7.2$ to
$\mathrm{pH} 5.3$, below which strain NRL38884 did not survive (Fig. 1). However, survival of the other three strains increased below $\mathrm{pH} 5.1$ to reach a peak (between $\mathrm{pH}$ 4.2 and 5.1) acid survival at $\mathrm{pH} 4.6-4.7$. The low $\mathrm{pH}$ peak was not an artefact of inoculation order or plating order. Furthermore, the peak was evident with and without $\mathrm{GC}$ broth supplement and $5 \mathrm{mM} \mathrm{NaHCO}_{3}$ added to the media, and in both autoclaved and filter sterilised media. The $\mathrm{pH}$ value of each of the acid survival cultures remained the same or changed by no more than $0.1 \mathrm{pH}$ unit during the 2 -h incubation period.

Stationary phase cultures of several enteric bacterial pathogens have been shown to be more acid resistant than log phase cultures [14-16]. Above $\mathrm{pH}$ 5.3, stationary phase cultures of gonococcal strains NRL38953 and NRL39029 were more acid resistant than $\log$ phase cultures, whereas the opposite was true for strain NRL38874 (data not shown). Stationary and $\log$ phase cultures of all three strains exhibited similar acid susceptibility below pH 5.3, except at pH 4.6-4.7 where $\log$ phase cells were more acid tolerant (data not shown). The latter corroborates the log phase $\mathrm{pH}$ 4.2-5.1 survival peak. The lower limit of survival for

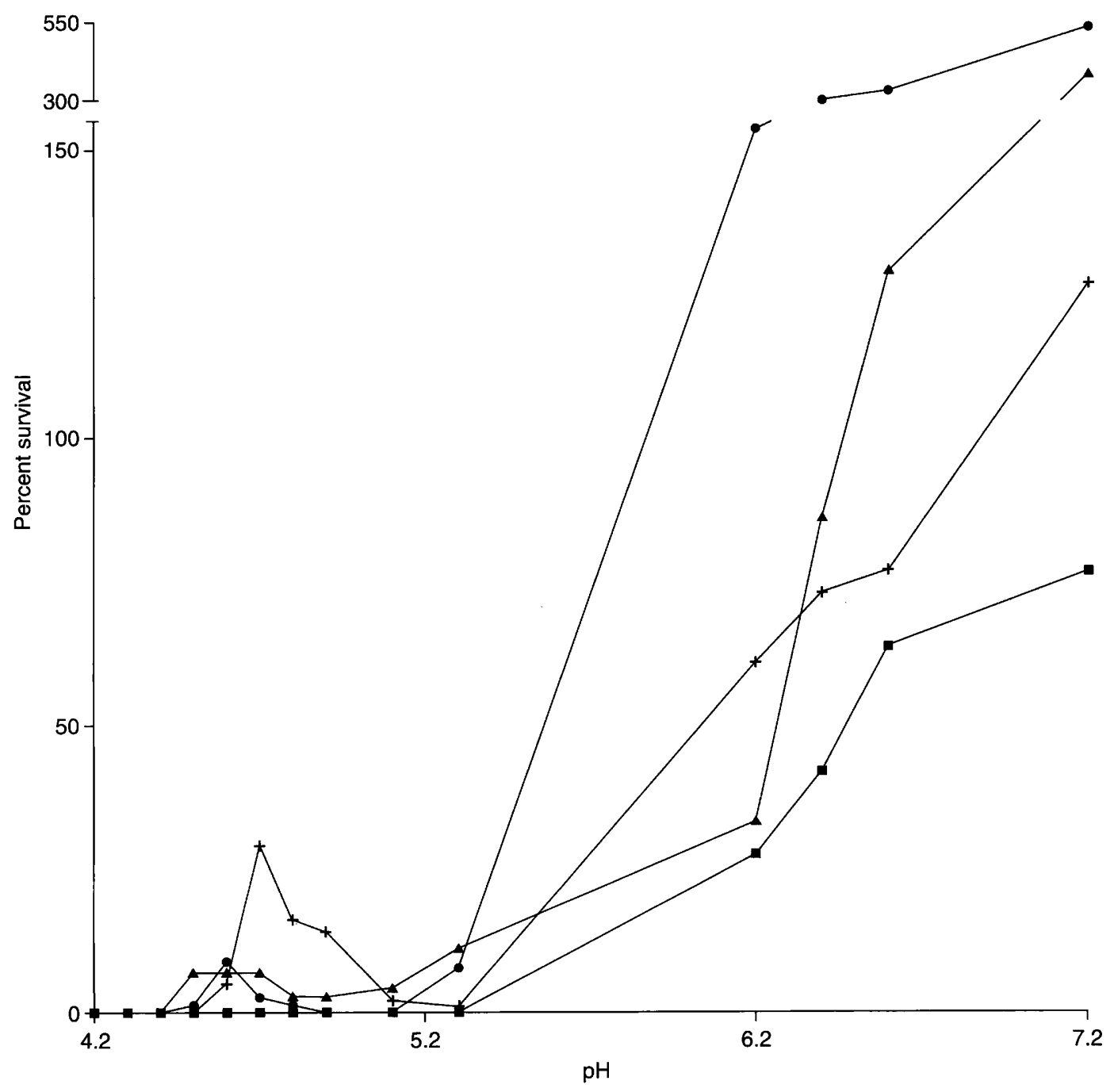

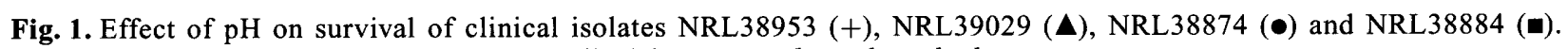
Percentage survival was calculated as described in Materials and methods. 
stationary and $\log$ phase cultures was typically $\mathrm{pH} 4.5$. The study attempted to compare acid survival of stationary and log phases of strain NRL38884, but the strain proved too fastidious for the manipulations involved in this assay. Acid survival below $\mathrm{pH} 4.0$ was investigated with $\log$ and stationary phase cultures of strain NRL38874. No survivors were detected at $\mathrm{pH}$ $3.4,3.5,3.6,3.7,3.8,3.9$ or 4.0 for either culture.

\section{Analysis of protein expression under neutral and acidic conditions}

Plate-grown organisms were used to analyse protein expression, because bacteria grown in vitro on solid support resemble organisms grown in vivo in terms of growth rate, ultrastructure and antigenic and biochemical characteristics [17]. For example, gonococcal cells grown in vivo, or at $\mathrm{pH} 6$ in vitro, both have membrane layers in close proximity [18]. Growth of the four strains on plates was undetectable below $\mathrm{pH} \mathrm{5.8;} \mathrm{the}$ amount of growth at $\mathrm{pH} 6.1$ was similar to that at $\mathrm{pH}$ 7.2 , suggesting that the protein differences described below are not due to slow growth. Furthermore, a previous study showed that the Sarkosyl-insoluble protein profile of glucose-deprived (i.e., relatively slow growth) gonococcal strain FA19 is different from that of acid-cultured strain FA19 [5]. SDS-PAGE gels revealed many protein differences in strains cultured under conditions differing only in medium $\mathrm{pH}$. However, only those acid stress proteins upregulated in at least three strains (arrows) or downregulated in all four strains (x) are indicated in Fig. 2. In whole-cell lysates of acid-grown strains NRL38953, NRL39029 and NRL38874, a protein migrating just ahead of the 66$\mathrm{kDa}$ marker was upregulated (Fig. 2). Evidence that this protein is gonococcal hsp63 was obtained in immunoblots (Fig. 3a). Hsp63 was upregulated in total membrane fractions of all four acid-grown strains, but was not detectable in outer-membrane fractions. Of five StressGen antibodies (Victoria, BC, Canada) against bacterial hsps tested (anti-E. coli DnaK, anti-E. coli GroES, anti-E. coli GrpE, anti-E. coli DnaJ and anti$M$. tuberculosis Hsp71), only anti-E. coli DnaJ $(41 \mathrm{kDa})$ recognised a protein of similar molecular mass in gonococcal preparations. The expression of this protein appeared equivalent under both growth conditions and, like hsp63, was detected only in wholecell and total membrane fractions (Fig. 3b).

In Fig. 2, the intense band migrating just ahead of the gonococcal outer-membrane porin protein, Por, is the reduction modifiable outer-membrane protein (OMP) Rmp. It was less abundant in acid grown outermembrane fractions of all four strains. Identical results were obtained with $N$. gonorrhoeae strain FA19 [5]. Silver-stained gels allowed visualisation of numerous upregulated and downregulated OMPs from strains grown under the two conditions (Fig. 4a). Only those proteins upregulated by acid stress in all four strains are marked (Fig. 4a, arrows).
Recognition of acid stress proteins by antibodies in serum from PID patients

Sera from patients with PID were assayed for the presence of specific antibodies to acid stress inducible and repressible OMPs. OMP blots were probed with NHS (Fig. 4b), and with serum from the patients infected with strains NRL38953 (Fig. 4c), NRL38884 (Fig. 4d), NRL39029 (Fig. 4e) and NRL38874 (Fig. 4f). Normal human serum IgG recognised several common outer-membrane constituents in the four isolates including Por, the outer-membrane lipoprotein Lip, and three acid stress upregulated proteins. Three acid stress inducible proteins of the same apparent molecular mass in the silver-stained gel and NHS blot were detected: two between the 66 and $86-\mathrm{kDa}$ markers, and one between the 33 and 45-kDa markers (Fig. $4 \mathrm{a}$ and $\mathrm{b}$ ). Anti-gonococcal antibodies in patients with no history of gonococcal infection are likely to be due to nasopharyngeal carriage of other Neisseria spp. [19]. Previous studies with serum from patients with gonorrhoea have described antibody recognition of Lip, Por and lipo-oligosaccharide (LOS) in strains cultured in neutral conditions [19]. In addition to these outermembrane constitutents, five distinct acid stress upregulated OMPs were recognised by IgG from PID patients in at least three strains (Fig 4c-f). Two acid stress inducible proteins between 47 and $86 \mathrm{kDa}$ were recognised by three of the PID sera (ICD082, ICD109, ICD108), and several proteins migrating to a position at or above the $139-\mathrm{kDa}$ marker were recognised by ICD102 (four proteins) and ICD108 (three proteins). These acid stress proteins cannot be described as completely novel, as they were expressed at low levels during growth in neutral conditions in some or all of the strains (depending on the protein). In the silverstained gel and NHS blot, there were no detectable ubiquitous acid stress repressible proteins. However, with ICD082 there were two acid stress repressible proteins between the 33 and $47 \mathrm{kDa}$ markers in all four strains (Fig. 4c, $x$ ). In Fig. 4, the apparent co-migration of Por and Lip was due to the outer-membrane isolation procedure, not the growth conditions (data not shown).

Immunoblots were also probed with PID sera followed by anti-human IgA. These blots resembled the NHS blot (data not shown). PID serum IgA recognition of proteins isolated from clinical and laboratory strains grown anaerobically is primarily directed against Por [20]. The limited antigen recognition by IgA compared with IgG in these acid and anaerobic experiments is probably due to the use of serum as the primary antibody.

\section{Discussion}

The acid survival of strain NRL38884 was remarkably different from that of the other three strains. As with other IA-1,2 serovars, NRL38884 is relatively fastidious 
a

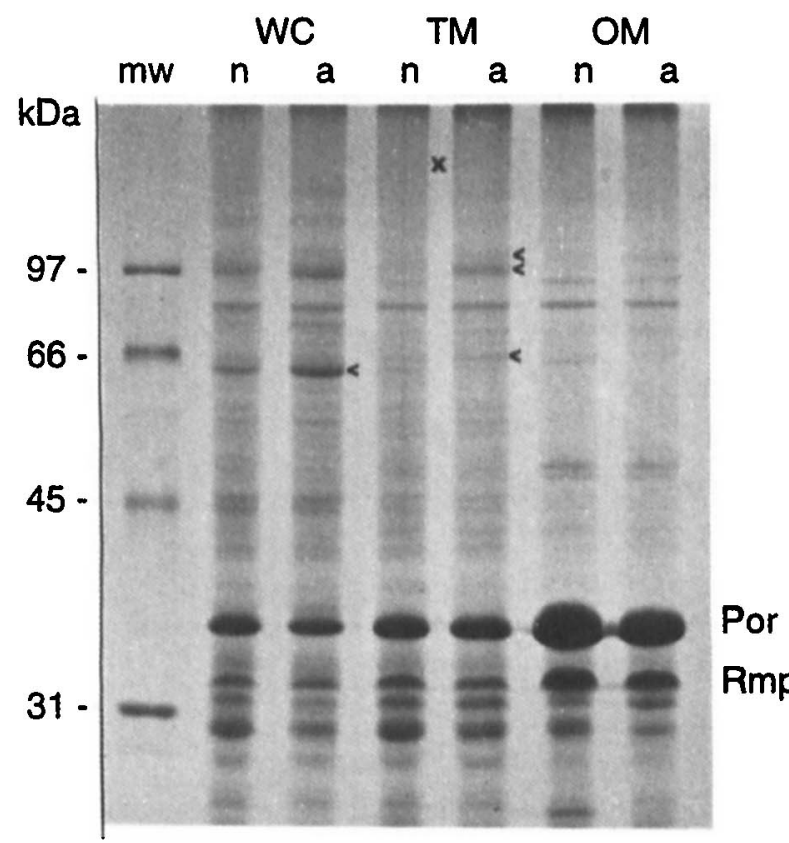

C

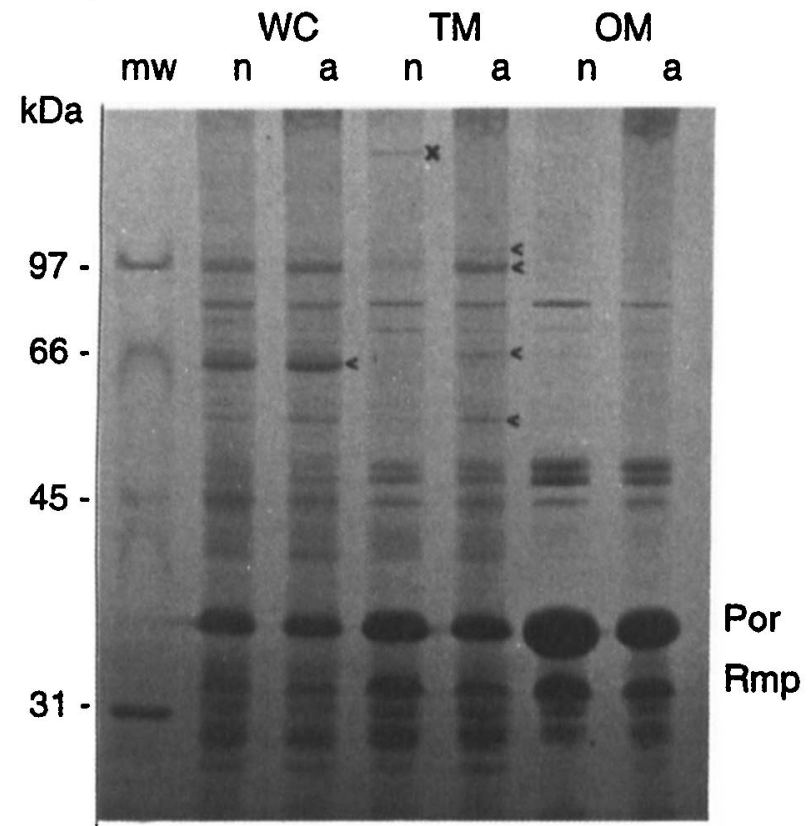

b

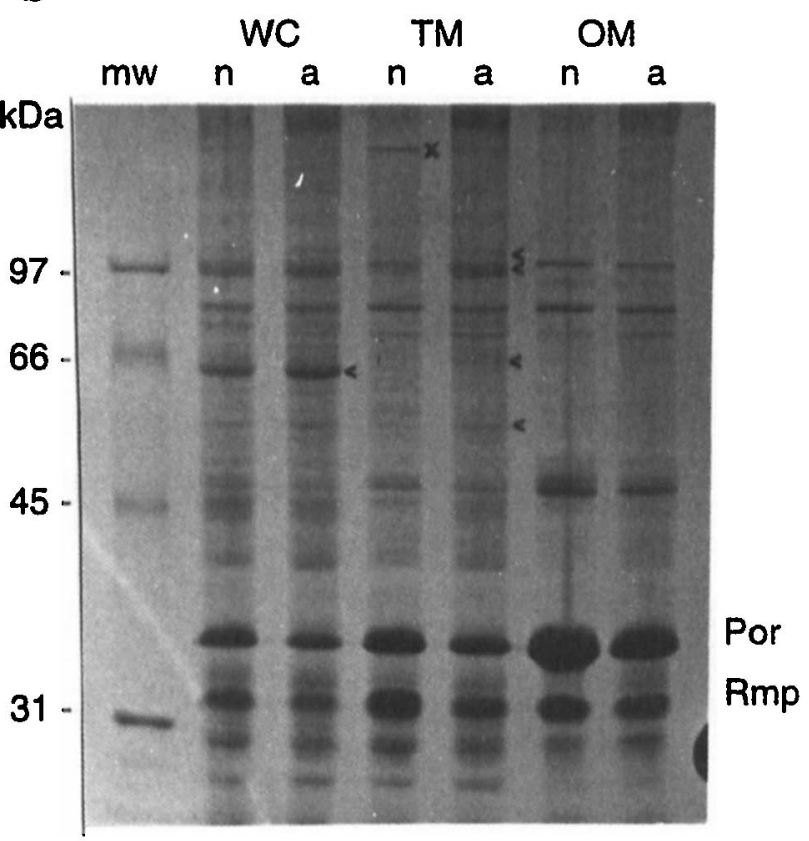

d
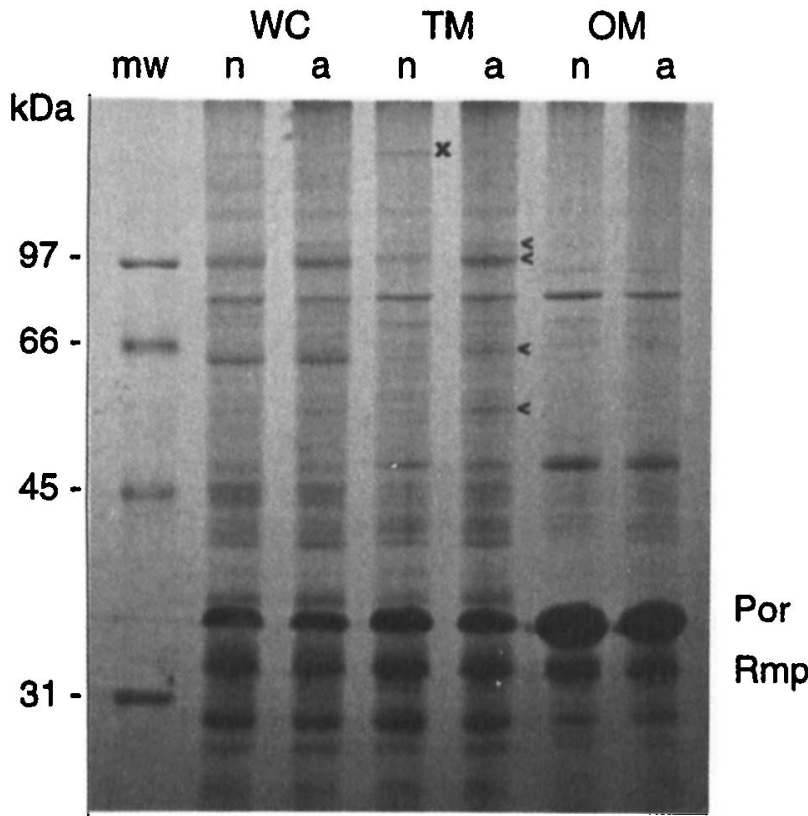

Fig. 2. Coomassie-stained SDS-PAGE $10 \%$ gels of whole-cell lysates (WC) (40 $\mu$ g protein/lane), total membranes (TM) $40 \mu \mathrm{g}$ protein/lane) and Sarkosyl-insoluble outer-membranes (OM) $(60 \mu \mathrm{g}$ protein/lane) from neutral (n) and acid (a) plate cultures of clinical isolates NRL38953 (a), NRL39029 (b), NRL38874 (c) and NRL38884 (d). mw, molecular mass markers (kilodaltons); Por, gonococcal porin protein; Rmp, gonococcal reduction modifiable protein; arrowheads denote acid stress upregulated proteins common to at least three of the four strains; $x$ denotes acid stress downregulated proteins common to the four strains.

and fragile [21], yet obviously capable of causing PID and stimulating the production of antibody directed against acid stress proteins. Log phase strains NRL38953, NRL39029 and NRL38874 had an unexpected low $\mathrm{pH}$ survival peak at $\mathrm{pH}$ 4.6-4.7. In similar experiments with Yersinia enterocolitica, survival decreased progressively from $\mathrm{pH} 6$ to 3 , with a survival peak between $\mathrm{pH} 4$ and $\mathrm{pH} 5$ of $\mathrm{pH} 4.5$ [15]. The authors did not discuss the peak in $Y$. enterocolitica, but their study used only a single strain, so the peak may have been considered an artefact. The abrupt change from neutral $\mathrm{pH}$ to $\mathrm{pH} 4.6-4.7$ in $N$. gonorrhoeae may be inducing a distinct acid tolerance system, apparently specific to log-phase growth. The phenomenon may be similar to that described for Salmonella serotype Typhimurium, a neutrophile that responds differently to moderate acid and severe acid conditions [22]. Future studies in this laboratory will include a determination of whether novel sets of proteins are expressed in moderately and severely acid-stressed $N$. gonorrhoeae. 
a

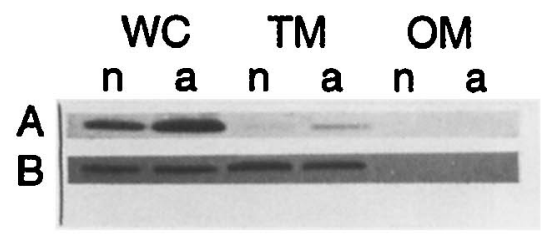

C

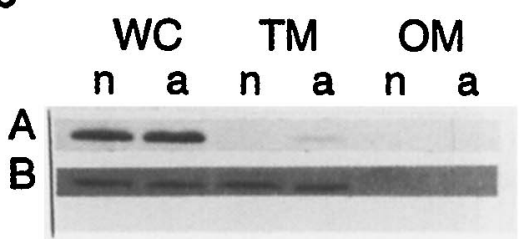

b

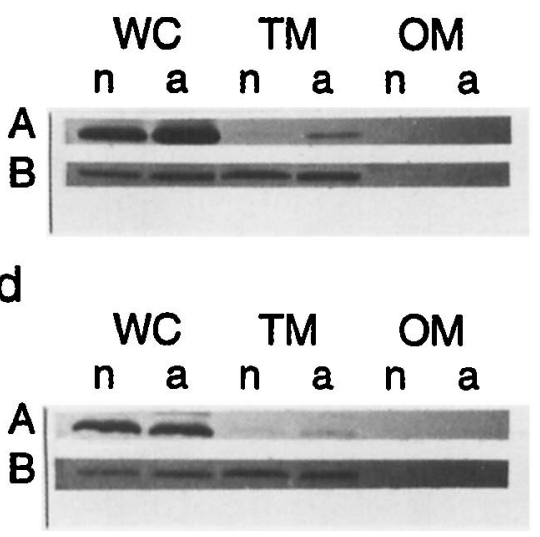

Fig. 3. Immunoblots of whole-cell lysates (WC) $(20 \mu \mathrm{g}$ protein/lane), total membranes (TM) (20 $\mu \mathrm{g}$ protein/ lane) and Sarkosyl-insoluble outer membranes (OM) $(30 \mu \mathrm{g}$ protein/lane) from neutral (n) and acid (a) plate cultures of clinical isolates NRL38953 (a), NRL39029 (b), NRL38874 (c) and NRL38884 (d). Immunoblots were probed with antiChlamydia hsp60 (A) or anti-E. coli hsp41 (B).

As bacteria enter the stationary phase, morphological and genetic changes occur to prolong survival and increase resistance to various stress conditions [23]. For example, stationary phase cultures of Shigella flexneri, $Y$. enterocolitica and $E$. coli are more acid tolerant than log-phase cultures [14-16]. The response of gonococcal PID isolates was more complex; the difference between $\log$ and stationary phase survival was strain and $\mathrm{pH}$ dependent.

A number of pathogenic bacteria are exposed to $\mathrm{pH}$ changes during the course of infection. To characterise total cellular protein expression at different $\mathrm{pH}$ values, some laboratories employ two-dimensional iso-electric focusing-SDS-PAGE of pulsed cells. The resulting protein profiles are typically a combination of known hsps and previously unrecognised stress proteins. For example, in response to growth at $\mathrm{pH} 5.5$, Brucella abortus synthesises almost 50 new proteins and upregulates 30 others, including DnaK and GroEL

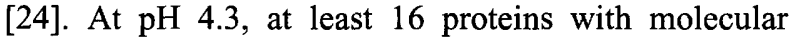
masses $>30 \mathrm{kDa}$ increase or are newly synthesised in E. coli [25]. This present study aimed to describe membrane protein profiles of cells cultured for many generations at low $\mathrm{pH}$. It was found that the more reproducible one-dimensional SDS-PAGE technique successfully documented many membrane protein differences between gonococcal clinical isolates cultured under neutral and acidic conditions. Depending on their cellular location, the acid stress proteins described may be involved in proton pumping, decreased membrane permeability, folding and transport of acid-damaged proteins, adhesion and immune evasion. OMPs would be directly exposed to an acid environment, and could potentially interact with the immune system, so their description was emphasised.

In acid-stressed gonococcal strains, the chaperone GroEL (gonococcal hsp63) was upregulated, as it is in nutrient-starved [2] and heat shocked [1] gonococ- cal strains. In contrast, the clinical isolates contained a protein related both antigenically and by molecular mass to $E$. coli DnaJ (41 kDa), that was apparently unaffected by acid stress. Nutrient- or oxygen-deprived gonococcal strain F62 increases the expression of several OMPs in the same electrophoretic range as the conserved hsp70 and hsp90 families [2]. Acid stress also induced the expression of OMPs in this electrophoretic range, in addition to at least four proteins $>100 \mathrm{kDa}$. The gonococcal OMP Rmp was less abundant in acid-grown cells, which may be relevant given that Rmp is a target for blocking $\mathrm{IgG}$ in human serum [26], and that $\mathrm{Rmp}$ is required by Opa+ gonococci (bearing opacity-associated proteins) for optimal adhesion and invasion of cultured cervical epithelial cells [27].

Acid-stress proteins can function as virulence factors. In Helicobacter pylori, hsp70 acts as an adhesin [28]. Increased level of surface hsp70 are responsible for sulphogalactosyl ceramide binding following $\mathrm{pH}$ shock of $H$. pylori, an event likely to be important in initial infection. Other evidence that $\mathrm{pH}$ affects bacterial virulence includes the mandatory acid $\mathrm{pH}$ induction of the ToxR regulon of Vibrio cholerae [29], the increased virulence of acid-grown $N$. meningitidis for mice [30], the $\mathrm{pH} 4.5$ optimum for adherence of intact gonococci and purified gonococcal pili to vaginal epithelial cells [7,8], and the $\mathrm{pH} 5.8$ optimum for the gonococcal sialyltransferase [9]. Some of the proteins upregulated in acid-cultured gonococcal strains may be involved in altered metabolic pathways and chaperone functions, but those described in Sarkosyl-insoluble fractions have the potential to interact with host tissues and immune defences. The fact that all four PID sera contained antibody to two or more acid stress upregulated OMPs suggests that these proteins are expressed in vivo. Currently studies are underway comparing the acid response of gonococcal clinical isolates with commensal strains of Neisseria. 
a $m w$ mw $n^{A} n^{B} a n^{C} a n^{D} a$

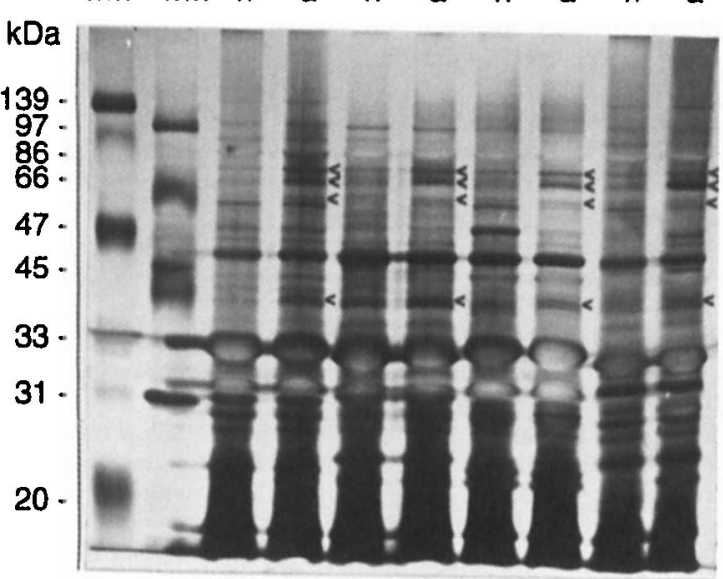

C

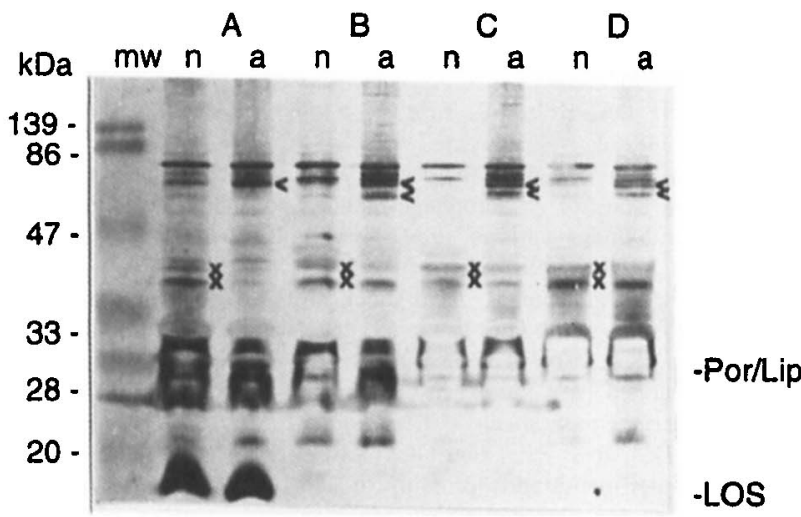

e

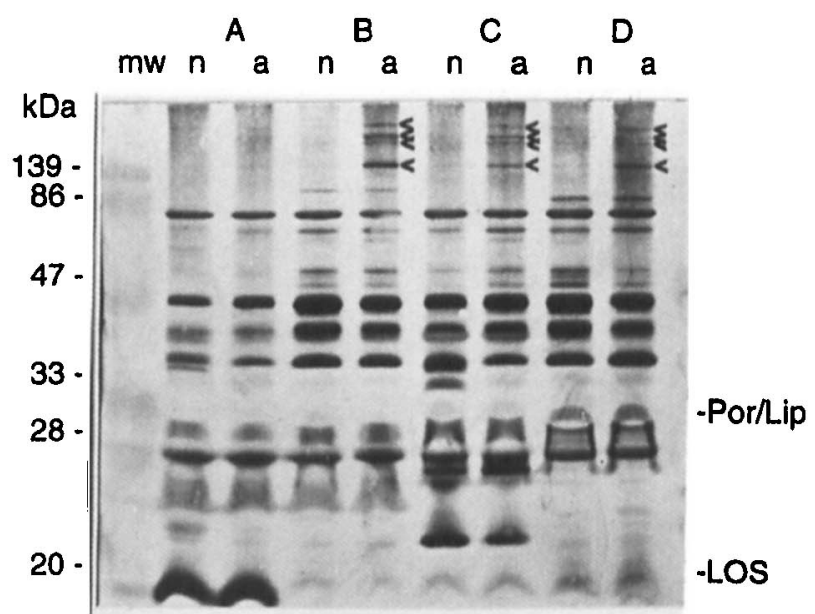

b

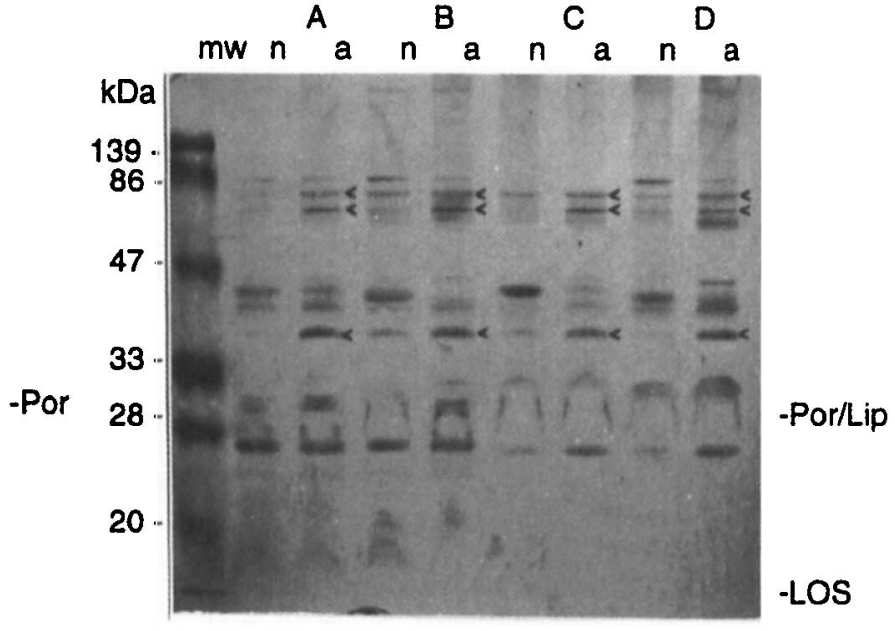

d

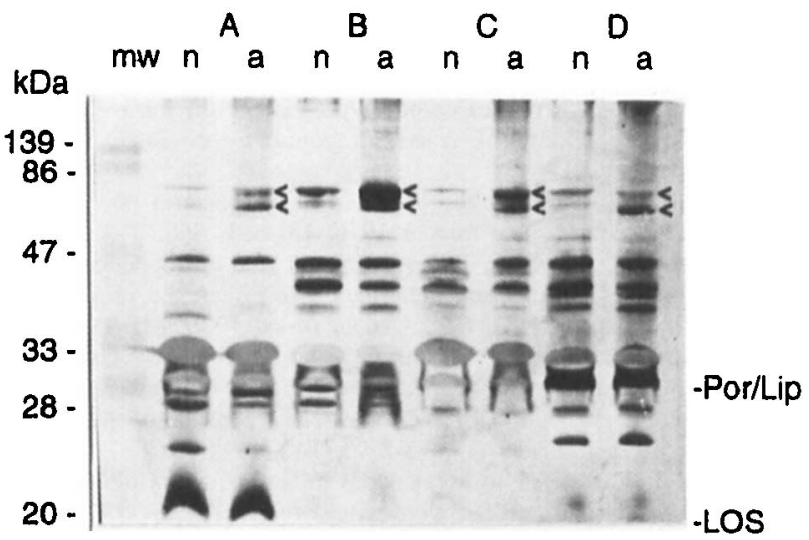

f

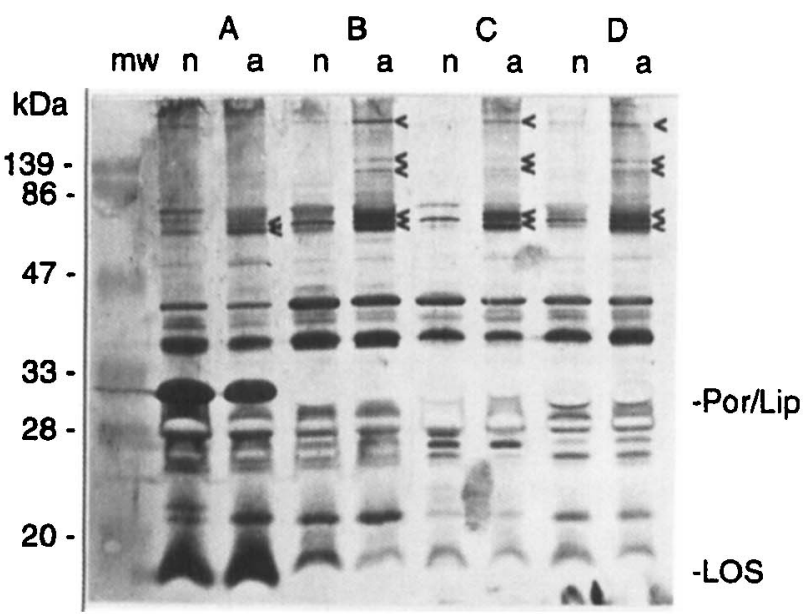

Fig. 4. Human serum IgG recognition of Sarkosyl- insoluble outer-membrane components (60 $\mu$ g protein/lane) from clinical isolates NRL38953 (A), NRL39029 (B), NRL38874 (C) and NRL38884 (D) cultured under neutral (n) and acidic (a) conditions. Panel a was stained with silver nitrate, and lanes 1 and 2 contain BioRad's pre-stained and nonpre-stained molecular mass markers, respectively. The immunoblots in panels $\mathrm{B}-\mathrm{F}$ were incubated with normal human serum (NHS) 7.5\% (b) or PID serum 7.5\% ICD082 (c), ICD109 (d), ICD102 (e), or ICD108 (f). Immunoblots contain pre-stained molecular mass markers $(\mathrm{mw})(\mathrm{kDa})$; Por/Lip, gonococcal porin protein/lipoprotein complex; LOS, lipooligosaccharide; arrowheads denote acid stress upregulated proteins common to at least three of the four strains; $\mathrm{x}$ denotes acid stress downregulated proteins common to the four strains. 
This work was supported by grant 1R15AI35745-01 from the NIH. We thank Ms Ruth Branch for assisting with acid survival control experiments, and $\mathrm{K}$. Konefal Winterscheid (Neisseria Reference Laboratory, Seattle, WA, USA) for providing strains and sera.

\section{References}

1. Woods ML, Bonfiglioli R, McGee ZA, Georgopoulos C. Synthesis of a select group of proteins by Neisseria gonorrhoeae in response to thermal stress. Infect Immun 1990; 58: 719-725.

2. Pannekoek Y, van Putten JP, Dankert J. Identification and molecular analysis of a 63-kilodalton stress protein from Neisseria gonorrhoeae. J Bacteriol 1992; 174: 6928-6937.

3. Clark VL, Campbell LA, Palermo DA, Evans TM, Klimpel KW. Induction and repression of outer membrane proteins by anaerobic growth of Neisseria gonorrhoeae. Infect Immun 1987; 55: 1359-1364

4. Zheng H, Hassett DJ, Bean K, Cohen MS. Regulation of catalase in Neisseria gonorrhoeae. Effects of oxidant stress and exposure to human neutrophils. J Clin Invest 1992; 90: $1000-1006$.

5. Pettit RK, Filiatrault MJ, Martin ES. Alteration of gonococcal protein expression in acidic culture. Infect Immun 1996; 64: 1039-1042.

6. Magnusson K-E, Kihlström E, Norlander L, Norqvist A, Davies $\mathrm{J}$, Normark S. Effect of colony type and $\mathrm{pH}$ on surface charge and hydrophobicity of Neisseria gonorrhoeae. Infect Immun 1979; 26: 397-401.

7. Mårdh PA, Weström L. Adherence of bacteria to vaginal epithelial cells. Infect Immun 1976; 13: 661-666.

8. Pearce WA, Buchanan TM. Attachment role of gonococcal pili. Optimum conditions and quantitation of adherence of isolated pili to human cells in vitro. J Clin Invest 1978; 61: 931-943.

9. Mandrell RE, Smith H, Jarvis GA, Griffiss JM, Cole JA. Detection and some properties of the sialyltransferase implicated in the sialylation of lipopolysaccharide of Neisseria gonorrhoeae. Microb Pathog 1993; 14: 307-313.

10. Swanson J. Studies on gonococcus infection. XII. Colony color and opacity variants of gonococci. Infect Immun 1978; 19: $320-331$.

11. Pettit RK, Martin ES, Wagner SM, Bertolino VJ. Phenotypic modulation of gonococcal lipooligosaccharide in acidic and alkaline culture. Infect Immun 1995; 63: 2773-2775.

12. Judd RC. ${ }^{125}$ I-peptide mapping of protein III isolated from four strains of Neisseria gonorrhoeae. Infect Immun 1982; 37: 622-631.

13. Yuan Y, Lyng K, Zhang Y-X, Rockey DD, Morrison RP. Monoclonal antibodies define genus-specific, species-specific, and cross-reactive epitopes of the Chlamydial 60-kilodalton heat shock protein (hsp-60): specific immunodetection and purification of Chlamydial hsp60. Infect Immun 1992; 60: 2288-2296
14. Benjamin MM, Datta AR. Acid tolerance of enterohemorrhagic Escherichia coli. Appl Environ Microbiol 1995; 61: 16691672.

15. De Koning-Ward TF, Robins-Browne RM. Contribution of urease to acid tolerance in Yersinia enterocolitica. Infect Immun 1995; 63: 3790-3795.

16. Gorden J, Small PLC. Acid resistance in enteric bacteria. Infect Immun 1993; 61: 364-367.

17. Lorian V. In vitro stimulation of in vivo conditions: physical state of the culture medium. $J$ Clin Microbiol 1989; 27: 2403-2406.

18. Hebeler BH, Wong W, Morse SA, Young FE. Cell envelope of Neisseria gonorrhoeae CS7: peptidoglycan-protein complex. Infect Immun 1979; 23: 353-359.

19. Hicks CB, Boslego JW, Brandt B. Evidence of serum antibodies to Neisseria gonorrhoeae before gonococcal infection. J Infect Dis 1987; 155: 1276-1281.

20. Clark VL, Knapp JS, Thompson S, Klimpel KW. Presence of antibodies to the major anaerobically induced gonococcal outer membrane protein in sera from patients with gonococcal infections. Microb Pathog 1988; 5: 381-390.

21. Hook EW, Handsfield HH. Gonococcal infections in the adult. In: Holmes KK, Mårdh P-A, Sparling PF, Wiesner PJ (eds) Sexually transmitted diseases, 2nd edn. New York, McGraw Hill. 1990: 149-165.

22. Foster JW. Salmonella acid shock proteins are required for the adaptive acid tolerance response. $J$ Bacteriol 1991; 173: 6896-6902.

23. Siegele DA, Kolter R. Life after log. J Bacteriol 1992; 174: 345-348.

24. Rafie-Kolpin M, Essenberg CR, Wyckoff JH. Identification and comparison of macrophage-induced proteins and proteins induced under various stress conditions in Brucella abortus. Infect Immun 1996; 64: 5274-5283.

25. Heyde M, Portalier R. Acid shock proteins of Escherichia coli. FEMS Microbiol Lett 1990; 69: 19-26.

26. Joiner KA, Scales R, Warren KA, Frank MM, Rice PA. Mechanism of action of blocking immunoglobulin $G$ for Neisseria gonorrhoeae. J Clin Infect 1985; 76: 1765-1772.

27. Bell DM, Rest RF, Chen GC, Gotschlich EC. PIII (Rmp, Class 4) outer-membrane protein of Neisseria gonorrhoeae is required for Opa-dependent adhesion and invasion of human epithelial cells. 97th Annual Meeting of the American Society for Microbiology, 1997: Abstract B-447.

28. Huesca M, Borgia S, Hoffman P, Lingwood CA. Acidic pH changes the receptor binding specificity of Helicobacter pylori: a binary adhesion model in which surface heat shock (stress) proteins mediate sulfatide recognition in gastric colonization. Infect Immun 1996; 64: 2643-2648.

29. Olson ER. Influence of $\mathrm{pH}$ on bacterial gene expression. $\mathrm{Mol}$ Microbiol 1993; 8: 5-14.

30. Brener D, DeVoe IW, Holbein BE. Increased virulence of Neisseria meningitidis after in vitro iron-limited growth at low pH. Infect Immun 1981; 33: 59-66. 